\title{
TITLE:
}

\section{Identification of minimal sequence for HIV-1 fusion inhibitors.}

\section{AUTHOR(S):}

Nishikawa, Hiroki; Oishi, Shinya; Fujita, Mizuno; Watanabe, Kentaro; Tokiwa, Rei; Ohno, Hiroaki; Kodama, Eiichi; ... Matsuoka, Masao; Otaka, Akira; Fujii, Nobutaka

\section{CITATION:}

Nishikawa, Hiroki ... [et al]. Identification of minimal sequence for HIV-1 fusion inhibitors.. Bioorganic \& medicinal chemistry 2008, 16(20): 9184-9187

\section{ISSUE DATE:}

2008-10-15

URL:

http://hdl.handle.net/2433/137210

\section{RIGHT:}

(C) 2008 Elsevier Ltd 


\section{Identification of minimal sequence for HIV-1 fusion inhibitors}

Hiroki Nishikawa, ${ }^{\mathrm{a}}$ Shinya Oishi, ${ }^{\text {a }}$ Mizuno Fujita, ${ }^{\mathrm{a}}$ Kentaro Watanabe, ${ }^{\text {a }}$ Rei Tokiwa, ${ }^{\mathrm{a}}$ Hiroaki Ohno,, Eiichi Kodama, ${ }^{\text {b }}$ Kazuki Izumi, ${ }^{\text {b }}$ Keiko Kajiwara, ${ }^{\text {b }}$ Takeshi Naitoh, ${ }^{\text {b }}$ Masao Matsuoka, ${ }^{\mathrm{b}}$ Akira Otaka, ${ }^{\mathrm{a}, \mathrm{c}}$ and Nobutaka Fujii ${ }^{\mathrm{a}, *}$

${ }^{a}$ Graduate School of Pharmaceutical Sciences, Kyoto University, Sakyo-ku, Kyoto 606-8501, Japan

${ }^{b}$ Laboratory of Virus Control, Institute for Virus Research, Kyoto University, Sakyo-ku, Kyoto 606-8507, Japan

${ }^{c}$ Graduate School of Pharmaceutical Sciences, The University of Tokushima, Tokushima 770-8505, Japan

*Corresponding author:

Nobutaka Fujii, Ph.D.

E-mail: nfujii@pharm.kyoto-u.ac.jp

Tel: $\quad+81-75-753-4551$

Fax: $\quad+81-75-753-4570$ 


\begin{abstract}
Emergence of multi-drug resistant HIV-1 is a serious problem for AIDS
\end{abstract}

treatment. Recently, the virus-cell membrane fusion process has been identified as a

promising target for the development of novel drugs against these resistant variants. In

this study, we identified a 29-residue peptide fusion inhibitor, SC29EK, which shows

activity comparable to the previously reported inhibitor SC35EK. Some residues in

SC29EK not required for interaction with virus gp41 heptad repeat 1 (HR1) were

replaced with an unnatural amino acid, 2-aminoisobutyric acid (Aib), to stabilize the

$\alpha$-helix structure and to provide resistance to peptidases.

Keywords: HIV-1; fusion inhibitor; $\alpha$-helix; heptad repeat. 


\section{Introduction}

Emergence of HIV-1 variants resistant to clinically approved inhibitors such as

reverse transcriptase (RT) or viral protease is a serious problem in AIDS treatment. ${ }^{1}$

Therefore, development of novel anti-HIV-1 drugs suppressing such resistant variants is

urgently required. In this regard, inhibitors that target other processes, including integration, receptor binding or fusion have been proposed to suppress such resistant variants. $^{2-6}$ We and others have recently focused on viral fusion to host cells for development of novel anti-HIV agents that effectively inhibit HIV-1 replication with fewer resistant variants and adverse side effects. ${ }^{7-9}$ Among envelope glycoproteins, gp41 in particular plays a pivotal role in the fusion process. Briefly, gp41 in trimer anchors to the host cell membrane, and two extra-virion $\alpha$-helical regions, designated as heptad repeats 1 and 2 (HR1 and HR2), form an anti-parallel 6-helix bundle by the interaction between HR1 and HR2, leading to fusion of HIV-1 with the cell membrane. ${ }^{10}$

Enfuvirtide (T-20) 1, which is derived from the gp41 HR2 region, is the only clinically approved peptide fusion inhibitor. ${ }^{11}$ Although this agent is effective against 
variants resistant to multiple RT- and protease- inhibitors as well as wild-type strains, ${ }^{12,13}$ T-20-resistant HIV-1 strains have emerged after T-20-containing therapy. ${ }^{14,15}$ Thus, the development of second generation fusion inhibitors that suppress T-20-resistant variants is urgently needed.

T-20 1 and another HR2 peptide C34 2 show the anti-HIV activity by binding with the viral gp41 HR1 to disturb the 6-helix bundle formation (Table 1). ${ }^{10 a}$ Previously, we developed the novel potent fusion inhibitors T-20EK ${ }^{16} 3$ and SC35EK ${ }^{9} \mathbf{4}$, which are derived from T-20 1 and C34 2, respectively. On the basis of the $\alpha$-helical structure of these HR2 peptides upon binding with HR1, ${ }^{17}$ we distinguished two surfaces: a virus HR1 interactive site and a solvent accessible site (Fig. 1). For the residues at the solvent-accessible site (b, c, f, g in Fig. 1), a series of systematic replacements with hydrophilic glutamic acid (E) or lysine (K) was introduced (EK motif) to enhance the $\alpha$-helicity of the HR2 peptides by possible intrahelical salt-bridges. On the other hand, the residues at the interactive site (a, d, e in Fig. 1) were retained for binding affinity. The stabilized bioactive $\alpha$-helix conformation led to 
increased anti-HIV-1 activity through higher affinity with the virus HR1 region. 2-Aminoisobutyric acid (Aib), which could enhance and/or stabilize $\alpha$-helicity of the peptides, ${ }^{18,19}$ and may confer peptidase resistance, ${ }^{20}$ was also applied to the modification of $\alpha$-helix inducible EK motifs.

In this study, we investigated the minimal sequence of C34 2 and SC35EK 4 for potent anti-HIV activity. In addition, modifications of each EK motif with Aib-containing motifs were examined.

\section{Results and discussion}

We and other groups have reported that C34 2 and its derivatives interact with N36, a representative peptide of the gp41 HR1 region. ${ }^{9,19,21}$ In these reports, N-terminal tryptophan rich domain (WRD) containing two tryptophan residues of C34 2 is essential for the interaction with the HR1 region, ${ }^{22}$ while the C-terminal sequence might not be important compared to the N-terminal. ${ }^{19,23}$ In order to identify the minimal N-terminal sequence of C34 2 and SC35EK 4, we designed two C-terminally truncated peptides 
C29 5 and C22 6 as well as the EK-motif-containing congeners SC29EK 7 and SC22EK

8, respectively (Table 1). The anti-HIV activity of these peptides was examined by MAGI assay. ${ }^{24,25}$ C29 5 and C22 $\mathbf{6}$ showed marginal activity compared to the original C34 2, ${ }^{19,26,27}$ while anti-HIV activity of SC29EK 7 possessing four EK motifs was comparable to that of C34 2 and SC35EK 4. Further truncation of an EK motif resulted in a significant decrease in anti-HIV activity (SC22EK 8; $\left.\mathrm{EC}_{50}=60 \mathrm{nM}\right)$. It is of note that SC29EK 7 and SC22EK 8 with EK motifs showed more potent activity than the original peptides C29 5 and C22 6, respectively.

The potent anti-HIV activity of HR2-derived fusion inhibitors can be rationalized by the facilitated bioactive $\alpha$-helix conformation, which is favorable for binding with the gp41 HR1 region. ${ }^{9,28}$ Wavelength-dependent circular dichroism (CD) spectra of SC29EK 7 at $25{ }^{\circ} \mathrm{C}$ showed characteristic spectrum minima at 208 and 222 $\mathrm{nm}$, which indicate the presence of a stable $\alpha$-helical conformation, as observed in SC35EK 4 (Fig. 2). On the other hand, SC22EK 8 showed slightly less $\alpha$-helicity compared with SC35EK 4 and SC29EK 7, indicating that the truncated sequence of 8 
may be insufficient to stabilize the $\alpha$-helix structure. Native peptides, C34 2, C29 5 and

C22 6 exhibited similar spectra indicating the random structure (Fig. 2).

The binding affinities were estimated by measuring the CD spectra of HR2 peptides 2 and 4-8 in the presence of equimolar amount of N36 (HR1 region peptide).

Similar spectra were observed in all N36/C34 derivative complexes except for the N36/C22 6 complex, indicating that these peptide mixtures contained the similar stable 6-helix conformation at $25{ }^{\circ} \mathrm{C}$ (Fig. 3). Less stable coiled-coil structure of the N36/C22 6 complex was consistent with the deficient anti-HIV activity of C22 6. Thermal stabilities of possible 6-helix bundle structures consisting of N36 and C34 derivatives were also evaluated by monitoring the CD signal at $222 \mathrm{~nm}$. Melting temperature $\left(T_{\mathrm{m}}\right)$ of the complex was defined as the midpoint of thermal unfolding transition state shown in CD profiles (Fig. 4). $T_{\mathrm{m}}$ values of N36/SC35EK 4, N36/SC29EK 7 and N36/SC22EK 8 mixtures were $71.5,65.0$ and $63.5^{\circ} \mathrm{C}$, respectively, which were higher than those of the corresponding mixtures of native sequences $\left[T_{\mathrm{m}}(\mathrm{N} 36 / \mathrm{C} 342)=52.5^{\circ} \mathrm{C}, T_{\mathrm{m}}(\mathrm{N} 36 / \mathrm{C} 29\right.$ 5) $=48.5^{\circ} \mathrm{C}$, and $T_{\mathrm{m}}\left(\mathrm{N} 36 / \mathrm{C} 22\right.$ 6) $\left.=38.5^{\circ} \mathrm{C}\right]$ (Fig. 4). These results indicate that the 
introduction of EK motifs to HR2 peptides enhances binding affinity with the HR1 region, which could provide more potent anti-HIV activity. It should be noted that SC22EK 8 showed less potent anti-HIV activity compared with the other EK motif-containing peptides, although the thermal stabilities were similar. The limited coverage of the HR1 region by the truncated sequence of $\mathbf{8}$ may be inadequate for complete inhibition against folding of viral gp41 even with high binding affinity. As such, the potent anti-HIV activity of SC29EK 7 is rationalized by the presence of minimal interactive residues as well as the stabilized bioactive $\alpha$-helix conformation induced by EK motifs.

Since the residues at the solvent accessible sites of HR2 peptides have no direct involvement in the interaction with the viral HR1 region, we expected that these EK motifs could be replaced with other $\alpha$-helix-inducible units. Replacement of a part of the EK motifs in SC29EK 7 with a pair of Aib-containing dipeptides such as Aib-Glu $(\boldsymbol{a} \boldsymbol{E})$ and Aib-Lys (aK) was attempted (peptides 9-12, Fig. 5, Table 2) ${ }^{18,20}$ Anti-HIV activities of the Aib-substituted peptides 9-12 were equipotent or lower compared with 
SC29EK 7. Peptide $\mathbf{9}$, which was modified with a pair of $\boldsymbol{a} \boldsymbol{E}$ and $\boldsymbol{a} \boldsymbol{K}$ dipepitides at the essential WRD of the HR2 peptide ${ }^{22}$ was the most potent, with the bioactivity almost identical to that of the parent SC35EK 4 (Table 2). This indicated that EK residues could be replaced with non-proteinogenic and $\alpha$-helix inducible Aib residues, which may also enhance the biostability in vivo. In order to investigate the effect of the remaining Glu-Lys pairing in the aE/aK motif, we further substituted these residues with glycine (Gly) (peptides 13-16) (Fig. 5, Table 2). All substituted peptides 13-16 showed significantly less potent anti-HIV activity compared with the corresponding peptides 9-12 containing an aE/aK motif (Table 2), suggesting that modification of an EK motif with two Aib-Gly ( $\boldsymbol{a} \boldsymbol{G})$ is not suitable for potent anti-HIV activity.

\section{Conclusions}

In this study, we identified the minimal bioactive sequence of HIV-1 fusion inhibitors and developed a novel potent fusion inhibitory peptide SC29EK 7 based on the previously reported SC35EK 4. SC29EK 7 reproduced potent anti-HIV-1 activity 
comparable to SC35EK 4. The introduction of $\alpha$-helix-inducible EK motifs to less

potent C29 5 recovered the bioactivity of the parent C34 2, indicating that binding of the C29 sequence containing essential tryptophan rich domain to the gp41 HR1 is sufficient for anti-HIV activity. Moreover, it was also demonstrated that some EK motifs are replaceable with other non-proteinogenic amino acids such as 2-aminoisobutyric acid (Aib). These results may lead to development of more potent HIV-1 fusion inhibitors.

\section{Experimental}

\subsection{Peptide synthesis}

Protected peptide-resins were manually constructed by Fmoc-based solid-phase

peptide synthesis. $t$-Bu ester for Asp and Glu;

2,2,4,6,7-pentamethyldihydrobenzofuran-5-sulfonyl (Pbf) for Arg; $t$-Bu for Thr; Tyr and Ser; Boc for Lys; and Trt for Gln, Asn, and His were employed for side-chain protection. Fmoc-amino acids were coupled using five equivalents of reagents 
[Fmoc-amino acid, $N, N^{\prime}$-diisopropylcarbodiimide (DIPCDI), and $\mathrm{HOBt} \cdot \mathrm{H}_{2} \mathrm{O}$ ] in $\mathrm{DMF}$ for $1.5 \mathrm{~h}$. Fmoc deprotection was performed with 20\% piperidine in DMF (2 x 1 min, 1 x 20 min). The resulting protected resin was treated with TFA/thioanisole/m-cresol/1,2-ethandithiol/ $\mathrm{H}_{2} \mathrm{O}$ (80:5:5:5:5) at room temperature for $2 \mathrm{~h}$. After removal of the resin by filtration, the filtrate was poured into ice-cold dry diethyl ether. The resulting powder was collected by centrifugation and washed with ice-cold dry diethyl ether. The crude product was purified by preparative HPLC on a Cosmosil 5C18-ARII preparative column (Nacalai Tesque, 20 x $250 \mathrm{~mm}$, flow rate $10 \mathrm{~mL} / \mathrm{min}$ ) to afford the expected peptides. All peptides were characterized by an ESI-MS (Sciex APIIIIE, Toronto, Canada) or MALDI-TOF-MS (AXIMA-CFR plus, Shimadzu, Kyoto, Japan), and the purity was calculated as $>95 \%$ by HPLC on a Cosmosil 5C18-ARII analytical column (Nacalai Tesque, 4.6 x $250 \mathrm{~mm}$, flow rate $1 \mathrm{~mL} / \mathrm{min}$ ) at $220 \mathrm{~nm}$ absorbance. The detailed MS data are shown in Table 3.

\subsection{Viruses and cells}

An infectious clone pNL4-3 (GenBank accession number: $\underline{\text { AF324493) }}$ was 
used for the construction and production of HIV-1 variants as described previously. ${ }^{29}$

A wild type HIV-1 was generated by transfection of pNL4-3 into $293 \mathrm{~T}$ cells.

HeLa-CD4-LTR- $\beta$-gal cells (MAGI cells) were kindly provided by Dr. Emerman through the AIDS Research and Reference Reagent Program, Division of AIDS, National Institute of Allergy and Infectious Disease (NIAID) (Bethesda, MD, USA).

\subsection{Anti-HIV-1 activity}

Anti-HIV-1 activity was determined by the multinuclear activation of a galactosidase indicator (MAGI) assay as described previously. ${ }^{24,25}$ Briefly, the MAGI cells $\left(10^{4}\right.$ cells/well) were seeded in flat bottom 96-well microtitre plates. The following day, the cells were inoculated with HIV-1 (60 MAGI units/well, yielding 60 blue cells after $48 \mathrm{~h}$ incubation) and cultured in the presence of various concentrations of peptide inhibitors in fresh medium. After $48 \mathrm{~h}$ incubation, all the blue cells stained with 5-bromo-4-chloro-3-indolyl- $\beta$-D-galactopyranoside (X-gal) in each well were counted. The activity of inhibitors was determined as the concentration that blocked HIV-1 replication by 50\% (50\% effective concentration [EC 50$]$ ). 


\subsection{CD measurement}

An HR2 peptide (peptides 2 and 4-8) was dissolved in PBS $\mathrm{pH} 7.4$ at a concentration of $10 \mu \mathrm{M}$. At the CD measurement of mixture of an HR1 peptide (N36) and an HR2 peptide or its analogues, the peptides were incubated at $37^{\circ} \mathrm{C}$ for $30 \mathrm{~min}$ (final concentration of both HR1 peptide and HR2 peptide was $10 \mu \mathrm{M}$ in PBS, pH 7.4). The wavelength-dependent of molar ellipticity [ $\theta$ ] was monitored at $25{ }^{\circ} \mathrm{C}$ as the average of eight scans, and the thermal stability of the HR1 and HR2 mixture was estimated by monitoring the change in the CD signal at $222 \mathrm{~nm}$ in a spectropolarimeter (Model J-710; Jasco, Tokyo, Japan) equipped with a thermoelectric temperature controller. The midpoint of thermal unfolding transition (melting temperature $\left[T_{\mathrm{m}}\right]$ ) of each complex was determined as described previously. ${ }^{9}$

\section{Acknowledgements}

This work was supported in part by grants for the Promotion of AIDS Research

from the Ministry of Health and Welfare and the Ministry of Education, Culture, Sports, 
Science, and Technology of Japan (E. K. and S. O.); a grant for Research for Health Sciences Focusing on Drug Innovation from The Japan Health Sciences Foundation (E. K., S. O., N. F. and M. M.); and the 21st Century COE program "Knowledge Information Infrastructure for Genome Science” (N. F. and H. N.). H. N. is grateful for the JSPS Research Fellowships for Young Scientists. Appreciation is expressed to Mr. Maxwell Reback (Kyoto University) for reading the manuscript. 


\section{References}

1. $\quad$ Calmy, A.; Pascual, F.; Ford, N. N. Engl. J. Med. 2004, 350, 2720.

2. $\quad$ Fatkenheuer, G.; Pozniak, A. L.; Johnson, M. A.; Plettenberg, A.; Staszewski, S.; Hoepelman, A. I.; Saag, M. S.; Goebel, F. D.; Rockstroh, J. K.; Dezube, B. J.; Jenkins, T. M.; Medhurst, C.; Sullivan, J. F.; Ridgway, C.; Abel, S.; James, I. T.; Youle, M.; van der Ryst, E. Nat. Med. 2005, 11, 1170.

3. Grinsztejn, B.; Nguyen, B. Y.; Katlama, C.; Gatell, J. M.; Lazzarin, A.; Vittecoq, D.; Gonzalez, C. J.; Chen, J.; Harvey, C. M.; Isaacs, R. D. Lancet 2007, 369, 1261.

4. $\quad$ Hazuda, D. J.; Young, S. D.; Guare, J. P.; Anthony, N. J.; Gomez, R. P.; Wai, J. S.; Vacca, J. P.; Handt, L.; Motzel, S. L.; Klein, H. J.; Dornadula, G.; Danovich, R. M.; Witmer, M. V.; Wilson, K. A.; Tussey, L.; Schleif, W. A.; Gabryelski, L. S.; Jin, L.; Miller, M. D.; Casimiro, D. R.; Emini, E. A.; Shiver, J. W. Science 2004, 305, 528.

5. Root, M. J.; Kay, M. S.; Kim, P. S. Science 2001, 291, 884.

6. Tagat, J. R.; McCombie, S. W.; Nazareno, D.; Labroli, M. A.; Xiao, Y.; Steensma, R. W.; Strizki, J. M.; Baroudy, B. M.; Cox, K.; Lachowicz, J.; Varty, G.; Watkins, R. J. Med. Chem. 2004, 47, 2405.

7. Bewley, C. A.; Louis, J. M.; Ghirlando, R.; Clore, G. M. J. Biol. Chem. 2002, 277, 14238.

8. Dwyer, J. J.; Wilson, K. L.; Davison, D. K.; Freel, S. A.; Seedorff, J. E.; Wring, S. A.; Tvermoes, N. A.; Matthews, T. J.; Greenberg, M. L.; Delmedico, M. K. Proc. Natl. Acad. Sci. U. S. A. 2007, 104, 12772.

9. Otaka, A.; Nakamura, M.; Nameki, D.; Kodama, E.; Uchiyama, S.; Nakamura, S.; Nakano, H.; Tamamura, H.; Kobayashi, Y.; Matsuoka, M.; Fujii, N. Angew. Chem. Int. Ed. Engl. 2002, 41, 2937.

10. (a) Chan, D. C.; Kim, P. S. Cell, 1998, 93, 681. (b) Eckert, D. M.; Kim, P. S. Annu. Rev. Biochem. 2001, 70, 777.

11. Matthews, T.; Salgo, M.; Greenberg, M.; Chung, J.; DeMasi, R.; Bolognesi, D. Nat. Rev. Drug Discov. 2004, 3, 215. 
12. Lalezari, J. P.; Henry, K.; O'Hearn, M.; Montaner, J. S.; Piliero, P. J.; Trottier, B.; Walmsley, S.; Cohen, C.; Kuritzkes, D. R.; Eron, J. J., Jr.; Chung, J.; DeMasi, R.; Donatacci, L.; Drobnes, C.; Delehanty, J.; Salgo, M. N. Engl. J. Med. 2003, 348, 2175.

13. Lazzarin, A.; Clotet, B.; Cooper, D.; Reynes, J.; Arasteh, K.; Nelson, M.; Katlama, C.; Stellbrink, H. J.; Delfraissy, J. F.; Lange, J.; Huson, L.; DeMasi, R.; Wat, C.; Delehanty, J.; Drobnes, C.; Salgo, M. N. Engl. J. Med. 2003, 348, 2186.

14. Poveda, E.; Rodes, B.; Toro, C.; Martin-Carbonero, L.; Gonzalez-Lahoz, J.; Soriano, V. Aids 2002, 16, 1959.

15. Wei, X.; Decker, J. M.; Liu, H.; Zhang, Z.; Arani, R. B.; Kilby, J. M.; Saag, M. S.; Wu, X.; Shaw, G. M.; Kappes, J. C. Antimicrob. Agents Chemother. 2002, 46, 1896.

16. Oishi, S.; Ito, S.; Nishikawa, H.; Watanabe, K.; Tanaka, M.; Ohno, H.; Izumi, K.; Sakagami, Y.; Kodama, E.; Matsuoka, M.; Fujii, N. J. Med. Chem. 2008, 51, 388.

17. Chan, D. C.; Fass, D.; Berger, J. M.; Kim, P. S. Cell 1997, 89, 263.

18. Karle, I. L.; Balaram, P. Biochemistry 1990, 29, 6747.

19. Sia, S. K.; Carr, P. A.; Cochran, A. G.; Malashkevich, V. N.; Kim, P. S. Proc. Natl. Acad. Sci. U. S. A. 2002, 99, 14664.

20. Yamaguchi, H.; Kodama, H.; Osada, S.; Kato, F.; Jelokhani-Niaraki, M.; Kondo, M. Biosci. Biotechnol. Biochem. 2003, 67, 2269.

21. Liu, S.; Lu, H.; Niu, J.; Xu, Y.; Wu, S.; Jiang, S. J. Biol. Chem. 2005, 280, 11259.

22. Chan, D. C.; Chutkowski, C. T.; Kim, P. S. Proc. Natl. Acad. Sci. U. S. A. 1998, 95, 15613.

23. Gochin, M.; Savage, R.; Hinckley, S.; Cai, L. Biol. Chem. 2006, 387, 477.

24. Kimpton, J.; Emerman, M. J. Virol. 1992, 66, 2232.

25. Kodama, E. I.; Kohgo, S.; Kitano, K.; Machida, H.; Gatanaga, H.; Shigeta, S.; Matsuoka, M.; Ohrui, H.; Mitsuya, H. Antimicrob. Agents Chemother. 2001, 45, 1539.

26. Ji, H.; Shu, W.; Burling, F. T.; Jiang, S.; Lu, M. J. Virol. 1999, 73, 8578.

27. Shu, W.; Liu, J.; Ji, H.; Radigen, L.; Jiang, S.; Lu, M. Biochemistry 2000, 39, 
1634.

28. Judice, J. K.; Tom, J. Y.; Huang, W.; Wrin, T.; Vennari, J.; Petropoulos, C. J.; McDowell, R. S. Proc. Natl. Acad. Sci. U. S. A. 1997, 94, 13426.

29. Nameki, D.; Kodama, E.; Ikeuchi, M.; Mabuchi, N.; Otaka, A.; Tamamura, H.; Ohno, M.; Fujii, N.; Matsuoka, M. J. Virol. 2005, 79, 764. 
Table 1. Sequences and anti-HIV activities of C34 and its derivatives, and $T_{\mathrm{m}}$ values of the mixture with N36.

\begin{tabular}{|c|c|c|c|c|}
\hline Peptide & & Sequence & $\mathrm{EC}_{50}(\mathrm{nM})^{\mathrm{a}}$ & $T_{\mathrm{m}}\left({ }^{\circ} \mathrm{C}\right)^{\mathrm{b}}$ \\
\hline T-20 & 1 & YTSLIHSLIEESQNQQEKNEQELLELDKWASLWNWF & 15 & N.D. ${ }^{\mathrm{c}}$ \\
\hline C34 & 2 & WMEWDREINNYTSLIHSLIEESQNQQEKNEQELL & 0.68 & 52.5 \\
\hline T-20EK & 3 & YTSLIEELIKKSEEQQKKNEEELKKLEEWAKKWNWF & 1.8 & N.D. ${ }^{c}$ \\
\hline SC35EK & 4 & WEEWDKKIEEYTKKIEELIKKSEEQQKKNEEELKK & 0.39 & 71.5 \\
\hline C29 & 5 & WMEWDREINNYTSLIHSLIEESQNQQEKN & 46 & 48.5 \\
\hline $\mathrm{C} 22$ & 6 & WMEWDREINNYTSLIHSLIEES & $>1000$ & 38.5 \\
\hline SC29EK & 7 & WEEWDKKIEEYTKKIEELIKKSEEQQKKN & 0.46 & 65.0 \\
\hline SC22EK & 8 & WEEWDKKIEEYTKKIEELIKKS & 60 & 63.5 \\
\hline
\end{tabular}


Table 2. Sequences and anti-HIV activities of SC29EK analogues containing aminoisobutyric acid (Aib) residue

\begin{tabular}{|c|c|c|}
\hline Peptide & Sequence & $\mathrm{EC}_{50}(\mathrm{nM})$ \\
\hline 7 & WEEWDKKIEEYTKKIEELIKKSEEQQKKN & 0.46 \\
\hline 9 & WaEWDaKIEEYTKKIEELIKKSEEQQKKN & 0.54 \\
\hline 10 & WEEWDKKI $\underline{a E Y T} \underline{a K I E E L I K K S E E Q Q K K N ~}$ & 2.15 \\
\hline 11 & WEEWDKKIEEYTKKI $\underline{a E} L I \underline{a K S E E Q Q K K N}$ & 0.87 \\
\hline 12 & WEEWDKKIEEYTKKIEELIKKSaEQQ $\underline{a K N}$ & 7.10 \\
\hline 13 & 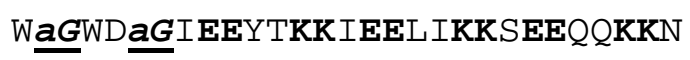 & 37.5 \\
\hline 14 & WEEWDKKI $\underline{a G} Y$ T $\underline{a G I E E L I K K S E E Q Q K K N}$ & 270 \\
\hline 15 & WEEWDKKIEEYTKKI $\underline{a G L I}$ I $\underline{\text { GSEEQQKKN }}$ & 25.6 \\
\hline 16 & WEEWDKKIEEYTKKIEELIKKSaGQQaGN & 31.3 \\
\hline
\end{tabular}

${ }^{\mathrm{a}} \mathrm{EC}_{50}$ was determined as the concentration that blocked HIV-1 replication by 50\%. 
Table 3. Mass spectrum data of synthesized peptides

\begin{tabular}{|c|c|c|c|}
\hline Peptide & Calc & ated $\mathrm{MW}\left(\mathrm{M}+\mathrm{H}^{+}\right)$ & Observed MW \\
\hline 1 & $\mathrm{C}_{204} \mathrm{H}_{302} \mathrm{~N}_{51} \mathrm{O}_{64}$ & 4492.9 & $4492.5^{a}$ \\
\hline 2 & $\mathrm{C}_{186} \mathrm{H}_{284} \mathrm{~N}_{51} \mathrm{O}_{64} \mathrm{~S}$ & 4290.6 & $4289.3^{a}$ \\
\hline 3 & $\mathrm{C}_{213} \mathrm{H}_{329} \mathrm{~N}_{52} \mathrm{O}_{63}$ & 4626.2 & $4625.5^{a}$ \\
\hline 4 & $\mathrm{C}_{203} \mathrm{H}_{326} \mathrm{~N}_{51} \mathrm{O}_{66}$ & 4537.1 & $4536.3^{a}$ \\
\hline 5 & $\mathrm{C}_{159} \mathrm{H}_{240} \mathrm{~N}_{45} \mathrm{O}_{54} \mathrm{~S}$ & 3677.9 & $3677.7^{\mathrm{a}}$ \\
\hline 6 & $\mathrm{C}_{125} \mathrm{H}_{185} \mathrm{~N}_{32} \mathrm{O}_{40} \mathrm{~S}$ & 2808.1 & $2808.1^{a}$ \\
\hline 7 & $\mathrm{C}_{170} \mathrm{H}_{270} \mathrm{~N}_{43} \mathrm{O}_{54}$ & 3780.2 & $3779.5^{\mathrm{a}}$ \\
\hline 8 & $\mathrm{C}_{134} \mathrm{H}_{210} \mathrm{~N}_{31} \mathrm{O}_{40}$ & 2895.3 & $2895.2^{\mathrm{a}}$ \\
\hline 9 & $\mathrm{C}_{167} \mathrm{H}_{265} \mathrm{~N}_{42} \mathrm{O}_{52}$ & 3693.1 & $3693.5^{\mathrm{b}}$ \\
\hline 10 & $\mathrm{C}_{167} \mathrm{H}_{265} \mathrm{~N}_{42} \mathrm{O}_{52}$ & 3693.1 & $3693.5^{\mathrm{b}}$ \\
\hline 11 & $\mathrm{C}_{167} \mathrm{H}_{265} \mathrm{~N}_{42} \mathrm{O}_{52}$ & 3693.1 & $3692.5^{\mathrm{b}}$ \\
\hline 12 & $\mathrm{C}_{167} \mathrm{H}_{265} \mathrm{~N}_{42} \mathrm{O}_{52}$ & 3693.1 & $3693.8^{\mathrm{b}}$ \\
\hline 13 & $\mathrm{C}_{160} \mathrm{H}_{252} \mathrm{~N}_{41} \mathrm{O}_{50}$ & 3550.0 & $3550.1^{\mathrm{b}}$ \\
\hline 14 & $\mathrm{C}_{160} \mathrm{H}_{252} \mathrm{~N}_{41} \mathrm{O}_{50}$ & 3550.0 & $3549.5^{b}$ \\
\hline 15 & $\mathrm{C}_{160} \mathrm{H}_{252} \mathrm{~N}_{41} \mathrm{O}_{50}$ & 3550.0 & $3550.2^{\mathrm{b}}$ \\
\hline 16 & $\mathrm{C}_{160} \mathrm{H}_{252} \mathrm{~N}_{41} \mathrm{O}_{50}$ & 3550.0 & $3550.2^{\mathrm{b}}$ \\
\hline
\end{tabular}




\section{Figure legends}

Figure 1. The design concept and helical wheel representation of HIV-1 gp41 HR2 peptide analogues. In the heptad repeat of $\alpha$-helix, positions a, d, e and positions b, c, f, g represent the viral HR1 interactive and solvent-accessible site, respectively.

Figure 2. CD spectra of HR2 peptide analogues.

Figure 3. CD spectra of HR2 peptide analogues in the presence of equimolar amount of N36.

Figure 4. Thermal midpoint analysis of CD signal at $222 \mathrm{~nm}$ for HR1 (N36) and HR2 peptide complex.

Figure 5. Substitution of an EE or KK unit with Aib-Glu (aE), Aib-Lys (aK) or Aib-Gly ( $a G)$. 


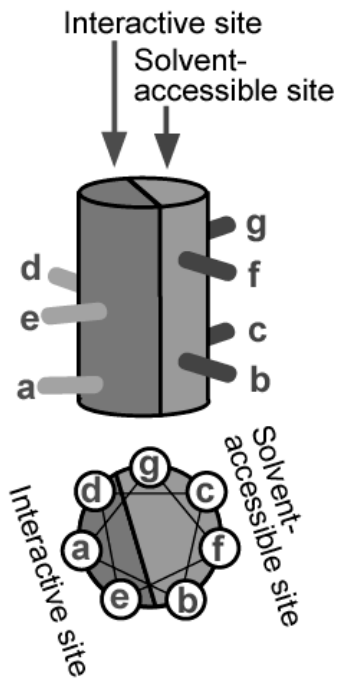

Figure 1. 


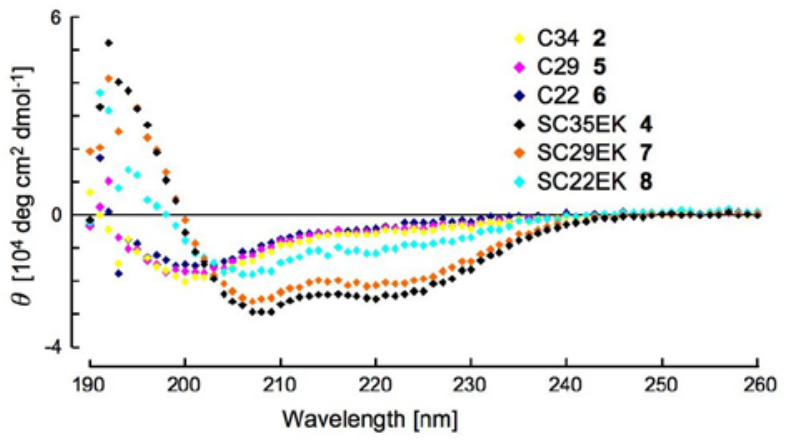

Figure 2.

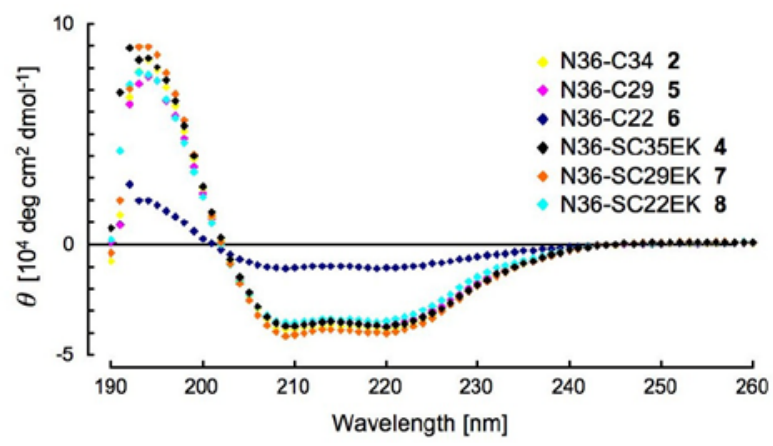

Figure 3. 


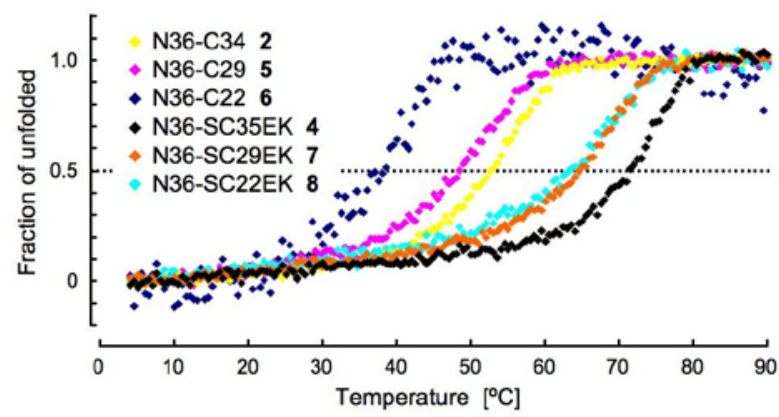

Figure 4.

Figure 5. 